\title{
Navigating Theological Resources
}

\section{A Webometric Content Analysis}

\author{
by Grace Andrews
}

\begin{abstract}
Using quantitative content analysis, this study assesses the navigability of a selection of Atla and Association of Christian Librarians library websites and measures the extent to which these libraries employ responsive design. The study finds that the most frequent navigational path for key content is in the main text of the landing page, either through a direct hyperlink or simply as text displayed on the website. Two-thirds (66\%) of the websites are found to be fully functional in their mobile versions, with only 5 (6\%) partially functional and $19(23 \%)$ not functional at all. The author concludes that theological libraries should consider their mission and resources when organizing their websites. Additionally, they should strive to include basic customer service and research assistance through their website. Putting key content in the main text of the homepage will make it more available to potential users. Libraries will do well to continue efforts toward responsive design.
\end{abstract}

\section{INTRODUCTION}

In the current information environment, a library's website is usually the first point of access for patrons (Ganski 2008, 38). Therefore, website design is crucial for designing a user-friendly library. However, it can be difficult, given the range of possibilities, for a library to know how to organize key components when revitalizing its current website or creating a website from scratch.

Libraries, like businesses, use their websites to provide information about themselves and to promote their services. However, with the increasing amount of digital information, a library's website often functions as a portal and not just a sign, offering users an "information gateway" through online catalogs and databases (McMenemy 2007, 656). The sheer amount of information a library has to organize on its website makes design difficult. Questions arise concerning the location and labeling of library contact information, operating hours, various services, policies, information about resources, and sometimes access to the resources themselves (Comeaux 2017, 10-11; Michalec 2006, 49).

For theological librarians, the task of designing a website is much the same as for academic or even public and school librarians. Creating and maintaining good "design, content, [and] usability," as well as keeping up with current website trends, are just as crucial for theological libraries as for other library types (Stephenson 2011, 89). It is important for a library website to act as an access point for patrons to engage with information (Stover 2001). Patrons of theological libraries can include local pastors and laity, so it is important to clearly organize free Internet materials and lists of open access resources as well as subscribed content. Authentication issues may arise, and library websites must provide instruction for who has what access and how patrons can use their authentication privileges. User-centered organization and design are paramount in fulfilling the library's mission online. Mark Stover states that the mission of the theological library is rooted in that of its parent institution, which is generally the tripartite academic "mission of research, teaching, and public service," with the added importance of religious identity (Stover 2001, 163). In supporting this mission, theological libraries fulfill the classic role of "collection, organization, and dissemination (or access)," focusing on material that will support theological education (Stover 2001, 169). Reflecting the theological library itself, the theological library website will likely include denominational archives and special collections, reference services, theologically focused collection development, technological support, resources for digital humanities work, "theological bibliography, and service to the broader religious community” (Stover 2001, 170).

In summary, theological library websites should be clearly organized with a structural framework that provides quick "context so that the user knows where he or she is" on the site (Stover 2001, 184). 
Design should balance utility and aesthetics to make for a pleasant online library experience. Kimberley Stephenson (2011) identified key library content as: user-oriented vocabulary; informational pages that describe operating hours, location, and contact information; reference and instruction pages, such as tutorials, citation and research guides, and reference chat; and research resources such as "databases, catalogs, and journal lists [which] are arguably the most important content elements on the library website" (Stephenson 2011, 90-1). The current study seeks to determine how such content is organized on theological library websites, presenting a pattern of navigation for libraries to consider and perhaps follow.

\section{PURPOSE STATEMENT}

This study employs webometric content analysis-a careful examination of the information communicated in a web context-to assess the navigability of a selection of Atla and Association of Christian Librarians theological library websites.

\section{RESEARCH QUESTIONS}

The following questions guide this study:

R1. What content appears most frequently on theological library homepages?

R2. What are the most frequent navigational paths to key content on theological library websites?

R3. To what degree is responsive design integrated into theological library websites?

\section{DEFINITIONS}

Atla: "Established in 1946 as the American Theological Library Association, Atla is a membership association of librarians and information professionals, and a producer of research tools, committed to advancing the study of religion and theology. Our membership includes more than 800 individuals and libraries at academic institutions from diverse religious traditions and backgrounds. As a community of collectors and connectors, Atla works to promote worldwide scholarly communication in religion and theology by advancing the work of libraries and related information providers" (Atla, n.d. "About Atla”).

Association of Christian Librarians (ACL): "An influential, vibrant, growing community, that integrates faith, ministry, and academic librarianship through development of members, services, and scholarship. The members of ACL are a diverse group of Christian librarians who serve in universities, colleges, seminaries, public libraries, and schools across the globe” (Association of Christian Librarians n.d., "About ACL”).

Atla institutional membership: "Institutional membership is open to libraries of institutions of higher education that support programs in theology and religious studies. The institution the library serves must be accredited by an authority recognized by the U.S. Department of Higher Education, Council of Higher Education Accreditation, or the equivalent thereof in other jurisdictions" (Atla n.d., "Institutional Membership").

Content analysis: "Close analysis of a work or body of communicated information to determine its meaning and account for the effect it has on its audience. Researchers classify, quantify, analyze, and evaluate the important words, concepts, symbols, and themes in a text (or set of texts) as a basis for inferences about the explicit and implicit messages it contains, the writer(s), the audience, and the culture and time period of which it is a part. In this context, 'text' is defined broadly to include books, book chapters, essays, interviews and discussions, newspaper headlines, periodical articles, historical documents, speeches, conversations, advertising, theater, informal conversation, etc” (Reitz n.d.). 
Navigability: The ease and efficiency of a user in finding desired or needed content on a website (Fang et al. 2006, 196).

Responsive design: The adaptability of a website to fit to various sizes of screens and types of devices (Tidal 2017, 17).

Webometric: A study which measures content, layout, and other facets of the web, analyzing websites, parts of websites, or the structure of the web itself (Thelwall 2009, 1).

\section{DELIMITATIONS}

This study seeks to assess the navigability of theological library websites. It includes only member libraries of Atla and ACL and is limited to the content of these websites; it does not examine user experience. The focus is on the placement and labeling of key library content such as homepages, catalogs, and online databases. Content is considered prominent if it appears on or is hyperlinked from the library homepage. Finally, responsive design is assessed for each website.

\section{ASSUMPTIONS}

It is assumed that the websites examined in this study are up-to-date and fully functional. This project also assumes, as did the 2014 study conducted by Salisbury and Griffis, that fewer clicks equate to easier navigability of a website (Salisbury and Griffis 2014, 594). Finally, this study assumes that the websites are user-oriented in their design and that there is, overall, a lack of unused content in prominent positions on the website. To paraphrase Ranganathan's second and third laws of library science, "Every user his or her web resource, and every web resource its user" (Noruzi 2004).

\section{IMPORTANCE OF STUDY}

Through this study's collection and analysis of trends in theological library website design, it may encourage more specific standards for the navigability of theological library websites. Although this study does not necessarily indicate what works best for users, it documents the relative ease and method of navigation across various theological library websites, giving libraries a place to start in website design. The project's findings and recommendations may be of interest to librarians, IT staff, and administrators at theological institutions, as well as faculty and students at these institutions.

\section{LITERATURE REVIEW}

Many library and information science (LIS) researchers have recognized the value of website design. As Ganski observes, "theological library websites serve as the virtual front door to the ever-increasing amount of electronic information for students, researchers, and faculty" (Ganski 2008, 38). Consequently, analyses of the content of library websites in different settings have contributed to the LIS literature over the past couple of decades. However, there is relatively little in the literature dedicated to theological library websites specifically. Therefore, this literature review will include studies on academic library web design and navigation, responsive design, and the website content analysis method generally rather than discussing theological libraries exclusively.

\section{Theological Library Websites}

A core study of theological library websites is Ganski’s 2008 assessment of e-resources. Through qualitative content analysis, she studied a selection of Atla and non-Atla websites for accessibility and navigation of online resources. At the time of the study, only a small majority of included sites linked to e-journals, 
but navigation was simple, generally less than three clicks from the homepage. The labels Ganski found for these resources were words like "full text," "online," "e-journal," and "Internet resources" (Ganski 2008, 41-2). The current study is very similar to Ganski's, exploring the navigation of certain features of theological library websites a decade later.

David Holifield (2012) took a different approach, focusing on Web 2.0 features of library websites. He challenged theological libraries to engage appropriately with social media platforms so that users of their websites feel more comfortable navigating the site and responding to library posts (Holifield 2012). This particular branch of website design differs from the core content navigation and responsive design that is the focus of the current study, but it demonstrates what has been studied relatively recently regarding theological library websites.

\section{Academic Library Design and Navigation}

Theological libraries fall within the broader category of academic libraries. Because of this, it is helpful to incorporate analyses of academic library websites into a study of theological library website design and navigation in order to gain perspective from the wider context. Studies of academic library websites are plentiful, covering navigation and core content on general and specialized websites. Kim and DeCoster conducted a study of business school library websites, focusing on access points and organization of the websites. Through qualitative content analysis, they found that access points to business databases were most frequently labeled as "Databases," "Research Guides/topics," "FAQs," "Top databases," and "Course guides." The most frequent organizational schemes were found to be alphabetical or topical by database or research guides by topic or resource type (Kim and DeCoster 2011, 139-40).

Noa Aharony (2012) assessed academic library website design over a ten-year period. Website content was analyzed according to a checklist that included site description, currency, website aids and tools, library general information, resources, services, links to e-resources, and value-added services (Aharony 2012, 768). This study found that library websites have increased their uses of graphics, copyright information, availability of reference sources, ask-a-librarian and reservation form services, links to e-journals, while decreasing their inclusion of an update date on web pages (Aharony 2012, 766-8).

Similar to Aharony, Anthony S. Chow, Michelle Bridges, and Patricia Commander (2014) employed a usability checklist and an online survey to study academic and public libraries, finding the common design features to be main navigation, oriented "horizontal[ly] and located at the top center of the page or vertically on the left side of the page; library logos . . located at the top of the page," contact/location information, and a search bar (Chow, Bridges and Commander 2014, 261). Additionally, common content included "contact information, directions, hours of operation, and access to their OPAC" (Chow, Bridges and Commander 2014, 262).

Salisbury and Griffis (2014) used content analysis to assess the presence of and navigation to mission statements on academic library websites. Building on the assumption that "web site content is hierarchical," this study counted clicks from a library's homepage to the mission statement-if present-to see how academic libraries tend to rank mission statements in terms of accessible content (Salisbury and Griffis 2014, 594). Of the $84 \%$ of library websites in the study that were found to contain mission statements, only one had a direct link to it (Salisbury and Griffis 2014, 594). However, 60\% contained two steps or fewer to reach the mission statement, suggesting that "libraries consider communication of mission or purpose an important task" (Salisbury and Griffis 2014, 596). Similarly, the present study uses the absence of multiple clicks as a measure of assessing the ease of navigation to major resources on theological library websites.

\section{Responsive Design}

In the last decade, the LIS community has researched the feasibility and implementation of responsive design; this has included studies gauging interest in accessing the library through a mobile device and the importance of such a move due to the ubiquity of mobile devices (Cummings, Merrill and Borelli 
2010; Rodriguez 2016). One crucial discovery of this research is that, to facilitate optimal navigation across devices, libraries must "weed nonessential content" from the website (Rodriguez 2016, 17).

Building on a previous study in 2015, Junior Tidal (2017) reported on a usability test for an academic library's responsive design. Using a combination of surveys and task-based tests, Tidal found that user experience was not uniform across devices. While core content was preserved, some facets on search pages and other advanced information were placed too far down on the mobile site for most smartphone users to scroll to. Coding for mobile devices, especially with smartphones in mind, will help libraries build more accessible websites (Tidal 2017, 25-31).

\section{Other LIS Website Content Analysis Studies}

Mychaelyn Michalec performed a content analysis that focused on design and content elements of both art museum library websites and academic/art school library websites, finding that art library websites generally had simple and legible design, although navigation was not always the most straightforward (Michalec 2006, 46-50). Daniel Earl Wilson used website content analysis to study academic library websites in Alabama, focusing on incorporation of social media/Web 2.0 tools and the library's OPAC (Wilson 2015, 99).

In 2016, Mohammed, Garba, and Umar conducted a content analysis of library websites in Nigeria with a view toward assessing strengths and weaknesses and offering recommendations for improvement. David J. Comeaux conducted a longitudinal study similar to Aharony's in 2012 in which he observed academic library websites, looking for both common content and the way design changed over a three-year period. His study identified common design features and noted that many libraries in the sample had already incorporated web-scale discovery tools by 2012 (Comeaux 2017, 9). Ayoung Yoon and Teresa Schultz conducted a library website content analysis to assess the ways in which libraries are involved in data management. Coding categories of data management in terms of "service, information, education, and network," this study determined that libraries engaged in data management would do well to provide more basic information, while continuing to engage in improved service, educational, and network-building opportunities (Yoon and Schultz 2017, 923).

\section{Conclusion}

While there are many studies featuring the content analysis method and likewise many observing various features of academic websites, comparatively little research could be located that focuses exclusively on theological library websites. This study builds on the content analysis methodology of the studies in this literature review, with a focus on points of access and navigation. In terms of taking note of what content exists on the websites, this study will follow the path of Still (2001), Aharony (2012), and Chow, Bridges and Commander (Chow, Bridges and Commander 2014). Building on these analyses of academic library websites and drawing on the work of Ganski (2008), the current study will focus specifically on theological libraries, analyzing the content and navigation of this sub-group.

\section{METHODOLOGY}

This study uses quantitative content analysis to evaluate the navigability of theological library websites.

\section{Data Collection and Analysis}

The data for this project were taken from the websites of Atla and ACL member libraries, with a focus on those specifically serving seminaries. To select the sample, first all ACL libraries with "seminary" in the title were compiled in a spreadsheet, totaling 45 libraries. This information was taken from the ACL Member Directory through member access to that part of the website (Association of Christian Librarians n.d., "Members by Institution"). Second, all Atla institutional member libraries with "seminary" in the title were marked in the $71^{\text {st }}$ Atla Summary of Proceedings Member Directory, counting all branches 
of a multi-branch or multi-campus library as one (Atla 2017, 264-70). Of these, libraries that were also ACL members were eliminated, resulting in 79 libraries. To make the distribution between ACL libraries and Atla libraries equal, the 79 Atla libraries were numbered, and Google's Random Number Generator was used to randomly select 45 of them. Finally, the 90 libraries, 45 ACL and 45 Atla, were combined in a spreadsheet and alphabetized as the foundation for further analysis.

Through careful, systematic examination of each website, first on a laptop computer and then on a mobile device for comparison of navigational path and display, answers to the research questions were stored in the alphabetized spreadsheet, organized by library. Results are grouped below by research questions and visualized with the aid of a bar graph, pie charts, and a table. To answer R1, content elements were listed and calculated for frequency of occurrence across library websites. Similar content was counted as one element, even if it was labeled differently on different websites; for example, any occurrence of a patron handbook, whether labeled "Patron Handbook," "Library Guide," or simply "First Time Here?" was counted as a patron handbook. For R2, the content items that occurred on more than half the websites analyzed in R1 were traced for navigational path, considering whether each item occurred most frequently in the main text of the website, in a menu, or as a dropdown from a menu. For R3, the website data were analyzed to determine whether or not a library incorporates responsive design, and then content and navigation data were recorded for the websites that have mobile versions to test functionality.

\section{Limitations}

This study was limited to Atla institutional member and ACL seminary library websites and therefore does not necessarily reflect the design of other types of theological library websites. Additionally, websites were analyzed for responsive design using first a laptop computer and then a smartphone, but they were not also tested with tablets or multiple brands of devices and operating systems. Finally, the project was limited to using only Google Chrome and Safari rather than assessing the relative navigability of each website in multiple browsers.

\section{RESULTS}

\section{R1. What content appears most frequently on theological library homepages?}

Of the 90 library websites selected for the original sample, eight were eliminated either because they were in a language other than English or because they were not found, bringing the sample size to 82 $(n=82)$. Thus, content was considered to be frequent if it appeared on more than 41 (over 50\%) of the websites. Seven distinct content items fit this criterion, including Operating Hours ( $n=73$, or 89\%), Research Databases ( $n=70$, or $85 \%)$, Writing and Citation Help ( $n=68$, or $83 \%)$, Library Catalog $(n=61$, or $74 \%)$, Contact Information ( $\mathrm{n}=58$, or $71 \%$ ), About the Library $(\mathrm{n}=55$, or $67 \%)$, and Subject Research Guides $(\mathrm{n}=48$, or $59 \%)$. These results are visualized in Figure 1 (following page).

\section{R2. What are the most frequent navigational paths to key content on theological library websites?}

The seven content items identified in R1 were analyzed in terms of layout and navigation. Since only content available on the homepage was considered in this project, each item required either one click or a hover and a click to access it. Each content item was analyzed to see how frequently it appeared in the main text of the webpage as compared to a menu or dropdown menu, as well as whether the menus were located at the top of the page, as a left sidebar, or as a right sidebar. To account for redundancy of content, each item was listed only in the first place it appeared on the website, scanning the page starting at the top left. 


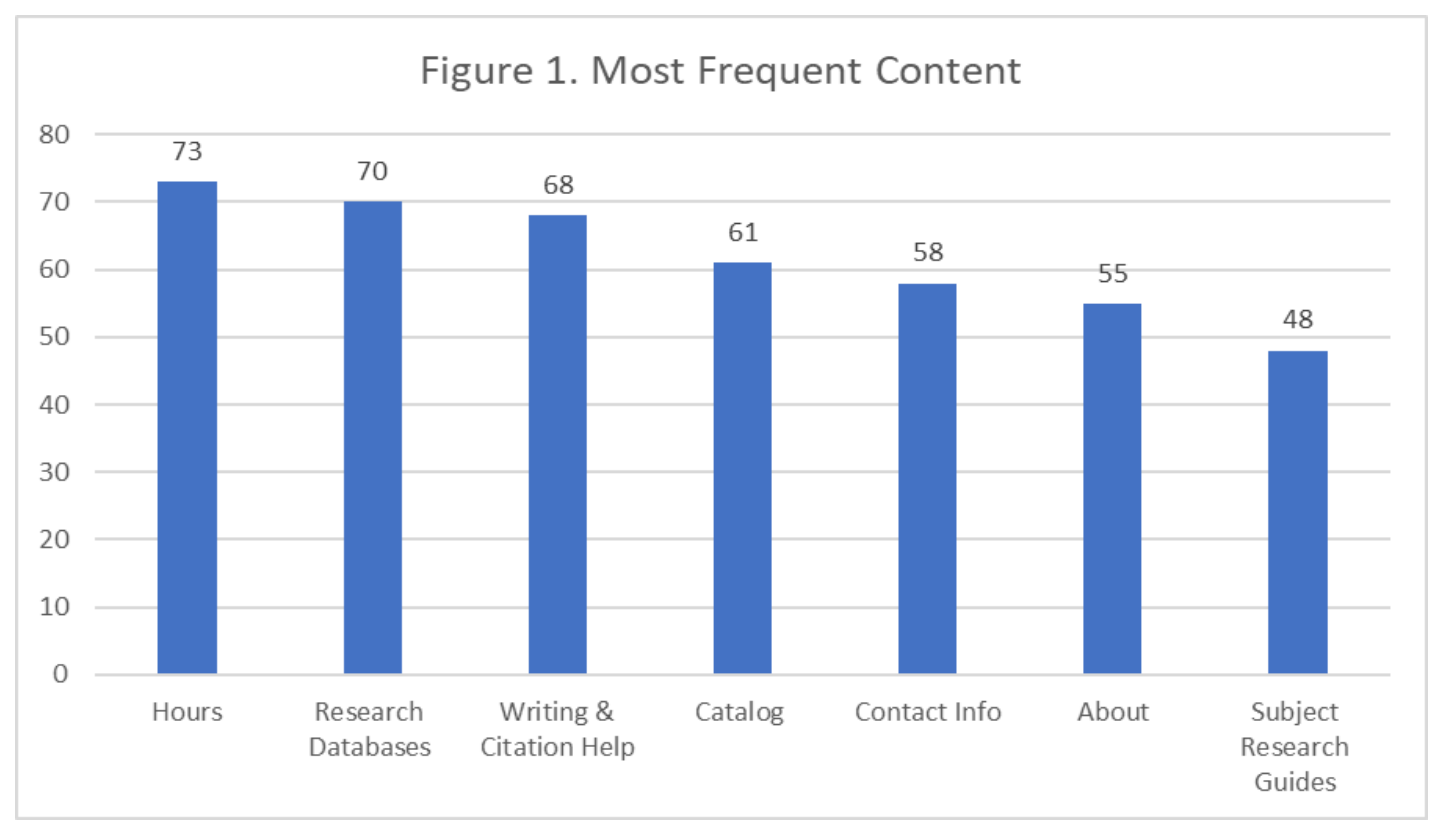

\section{OpERATING HOURS}

Operating Hours were found to be listed most frequently in the main text $(n=47$, or $64 \%)$. They were found less frequently on left $(n=12$, or $16 \%)$, right $(n=10$, or $14 \%)$, and top $(n=4$, or $6 \%)$ menus. These results are visualized in Figure 2.

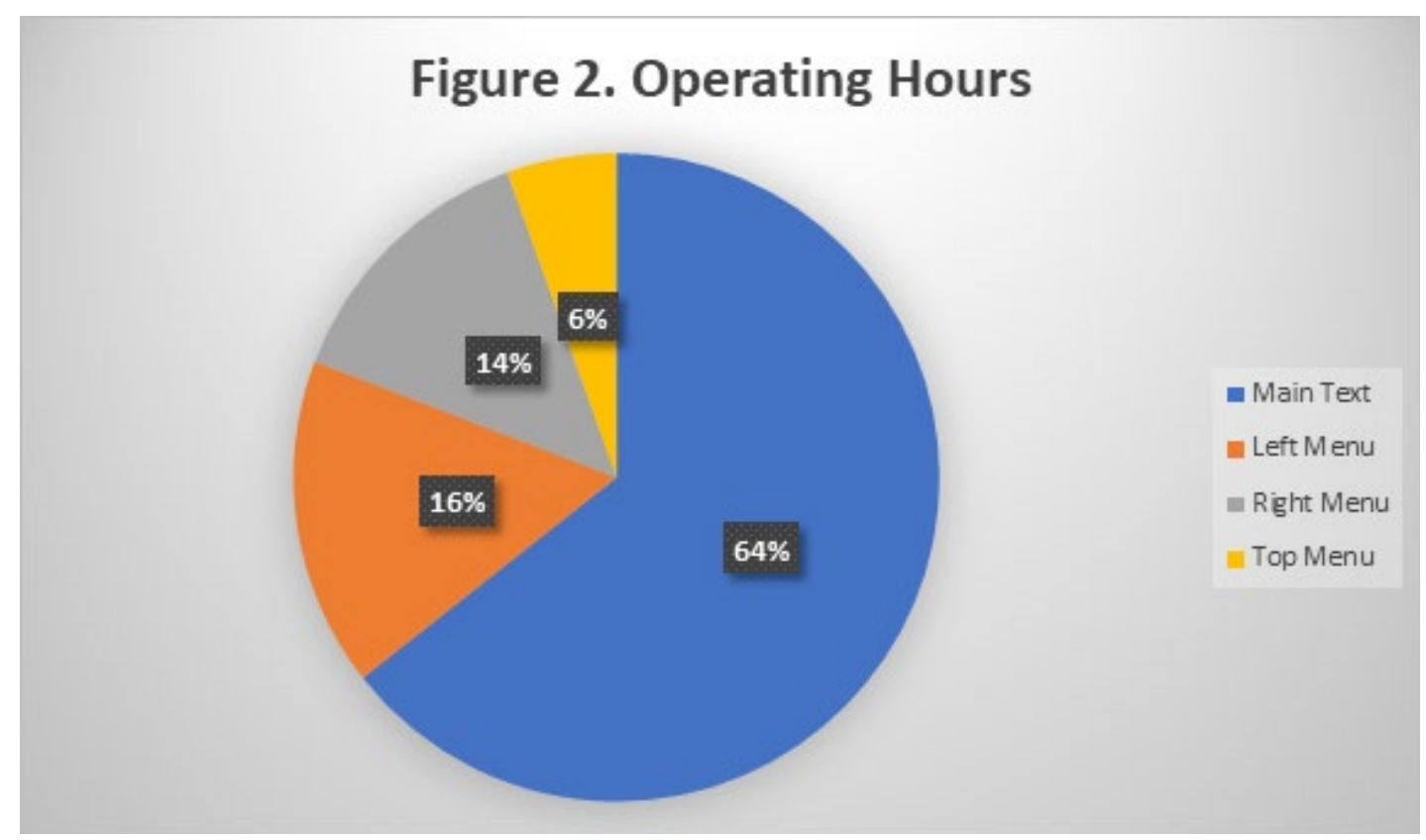




\section{RESEARCH DATABASES}

Research databases were also most frequently found in the main text of the website ( $n=51$, or $73 \%)$, with fewer occurrences of top dropdown menus $(n=7$, or $10 \%)$, right menus $(n=5$, or $7 \%)$, left menus ( $n=4$, or $6 \%$ ), top menus ( $n=2$, or $3 \%)$, and a left dropdown menu $(n=1$, or $1 \%)$. These results are visualized in Figure 3.

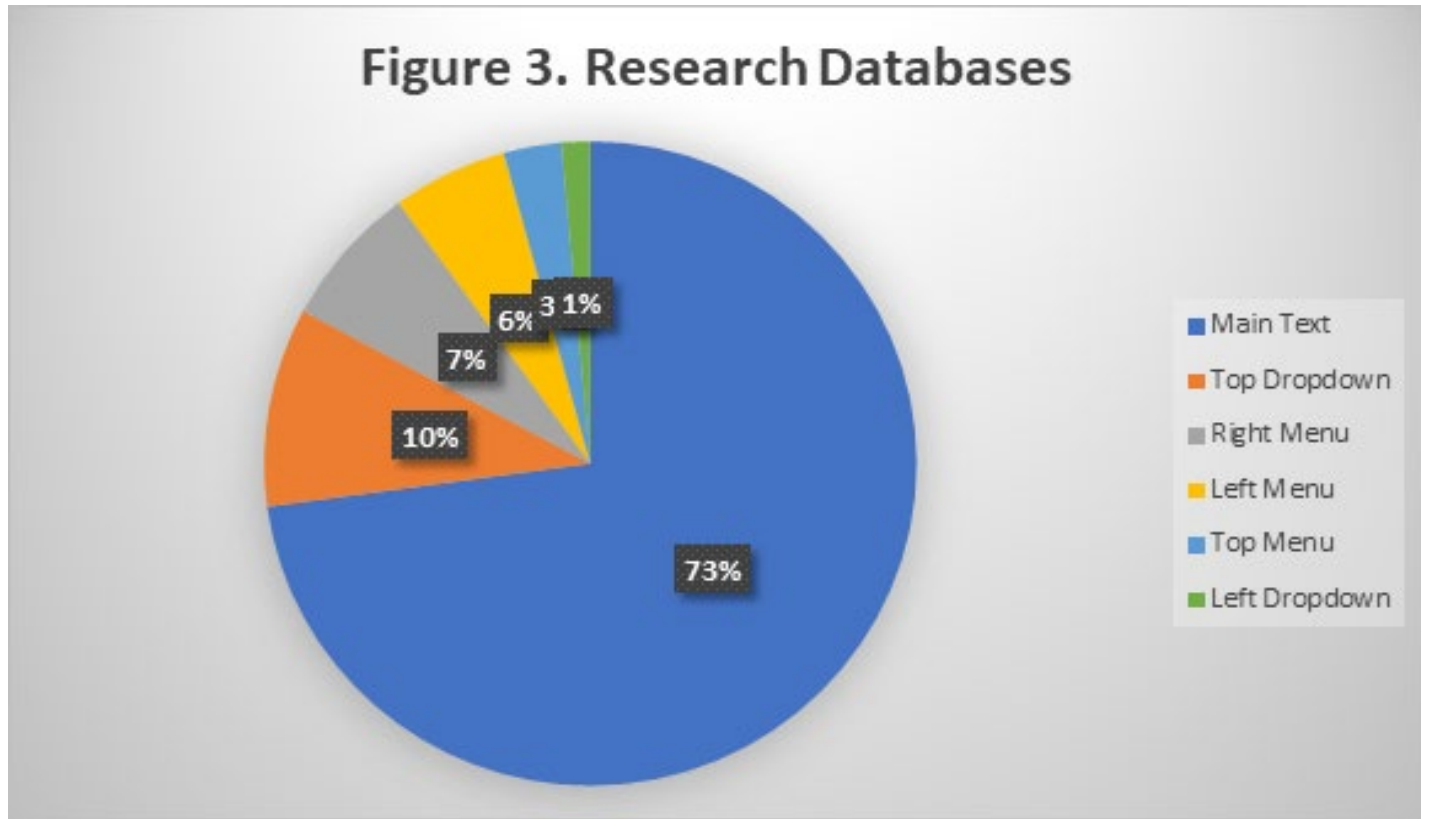

\section{Writing and Citation Help}

The main text of the website was the most common location for Writing and Citation Help ( $\mathrm{n}=25$, or $37 \%$ ), with less frequent but fairly evenly distributed occurrences of top menu ( $n=10$, or 15\%), top dropdown $(n=9$, or $13 \%)$, left menu ( $n=9$, or $13 \%)$, left dropdown $(n=6$, or $9 \%)$, right menu $(n=6$, or $9 \%)$, and right dropdown ( $n=3$, or 4\%). These results are visualized in Figure 4.

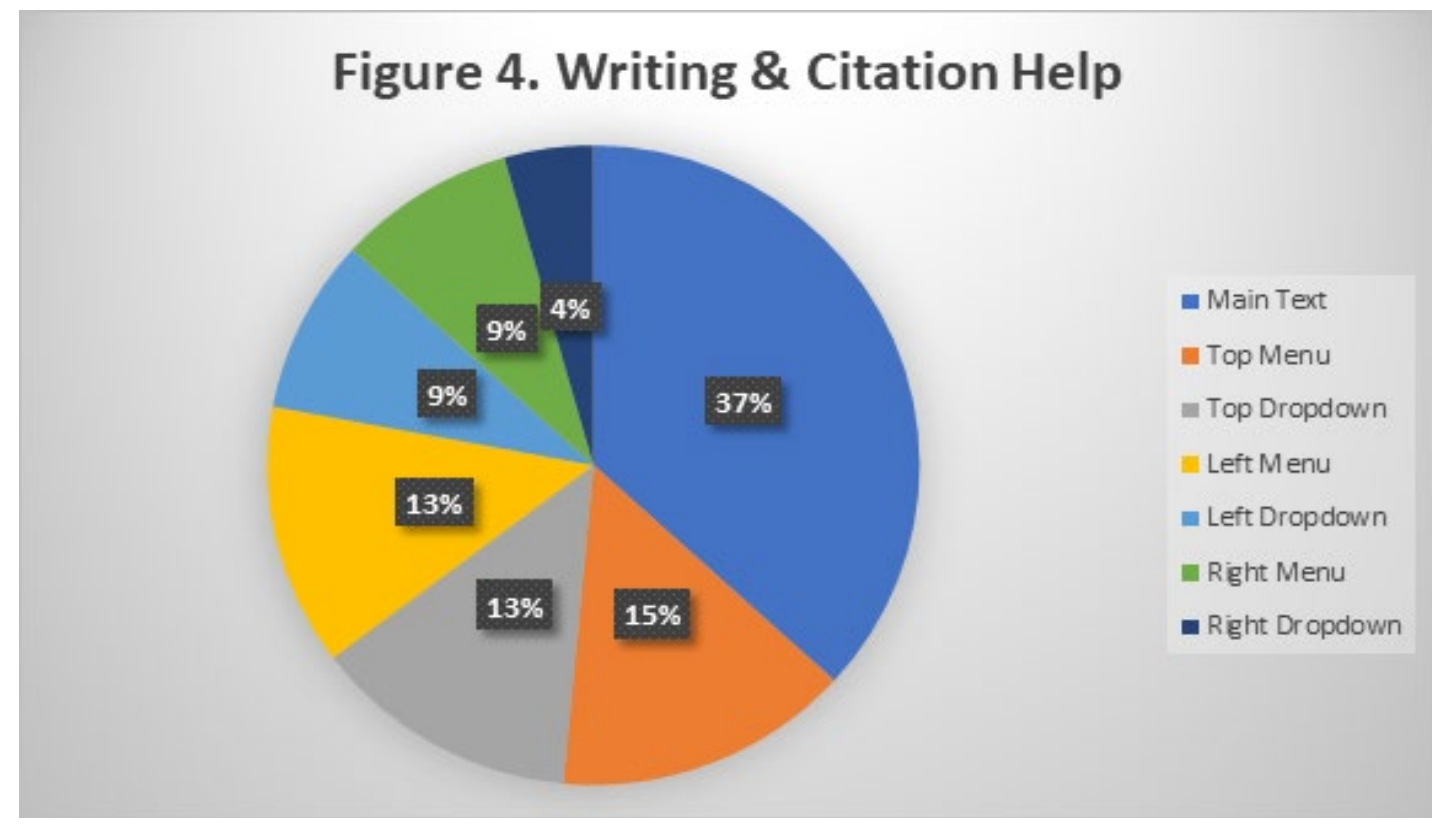




\section{LIBRARY CATALOG}

The library catalog was most frequently found in the main text ( $\mathrm{n}=49$, or $80 \%)$, either through a direct link, a discovery tool, or because the site simply was the catalog. A minority of websites located the catalog on a top, left, or right menu ( $\mathrm{n}=3$ each, or $5 \%$ ), with even fewer putting it in a top dropdown ( $\mathrm{n}=2$, or $3 \%)$ and 1 website locating it in a left dropdown (2\%). These results are visualized in Figure 5.

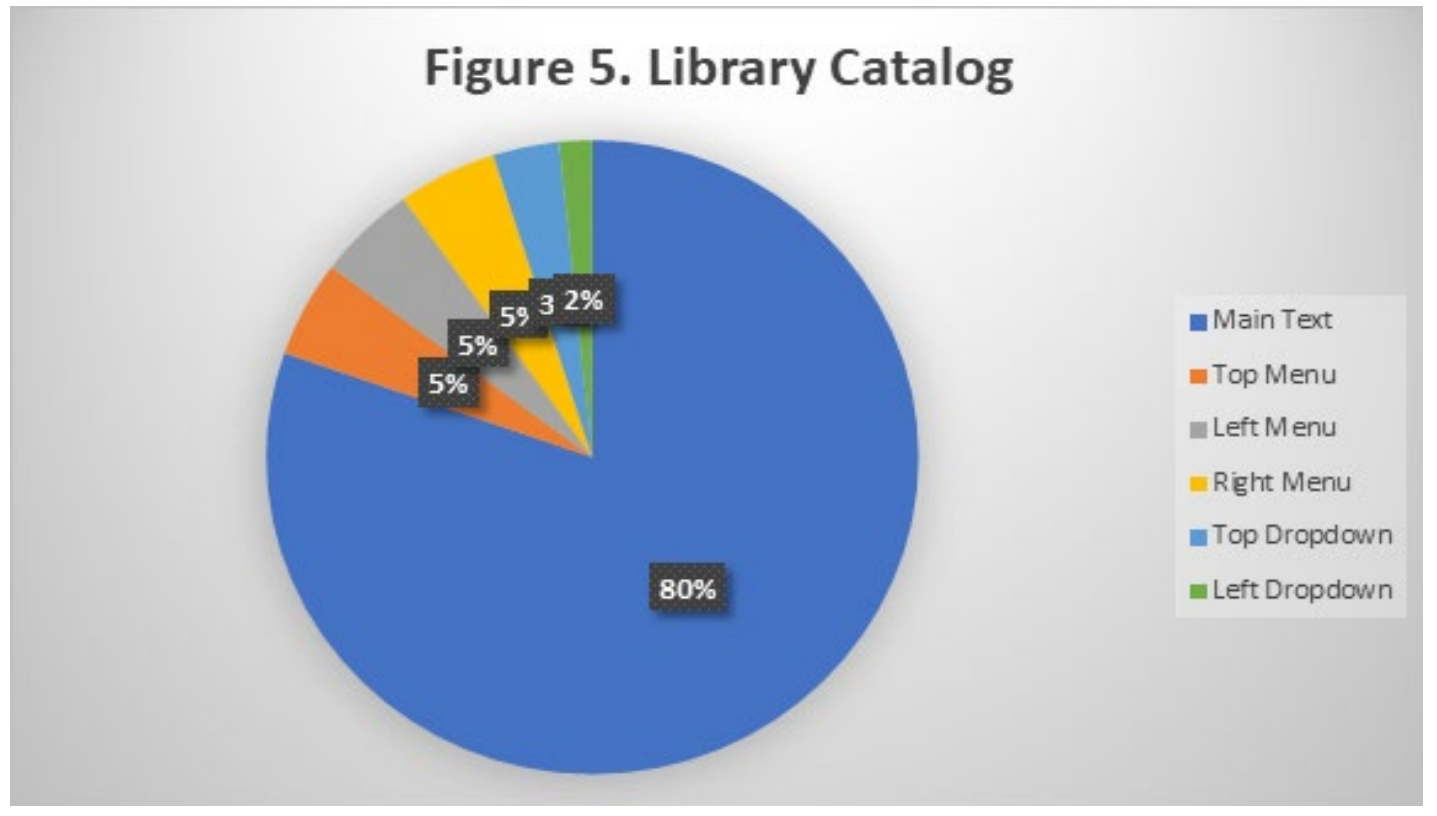

\section{CONTACT INFORMATION}

Again, the main text was the most frequent location for contact information ( $n=33$, or 57\%), with very few websites putting it in left menus ( $n=6$, or $10 \%)$, top dropdowns $(n=5$, or $8 \%)$, right menus ( $n=5$, or $9 \%)$, top menus $(n=3$, or $5 \%)$, and a left dropdown $(n=1$, or $2 \%)$. Additionally, contact information was sometimes located in the footer of the website $(n=5$, or $9 \%)$. These results are visualized in Figure 6.

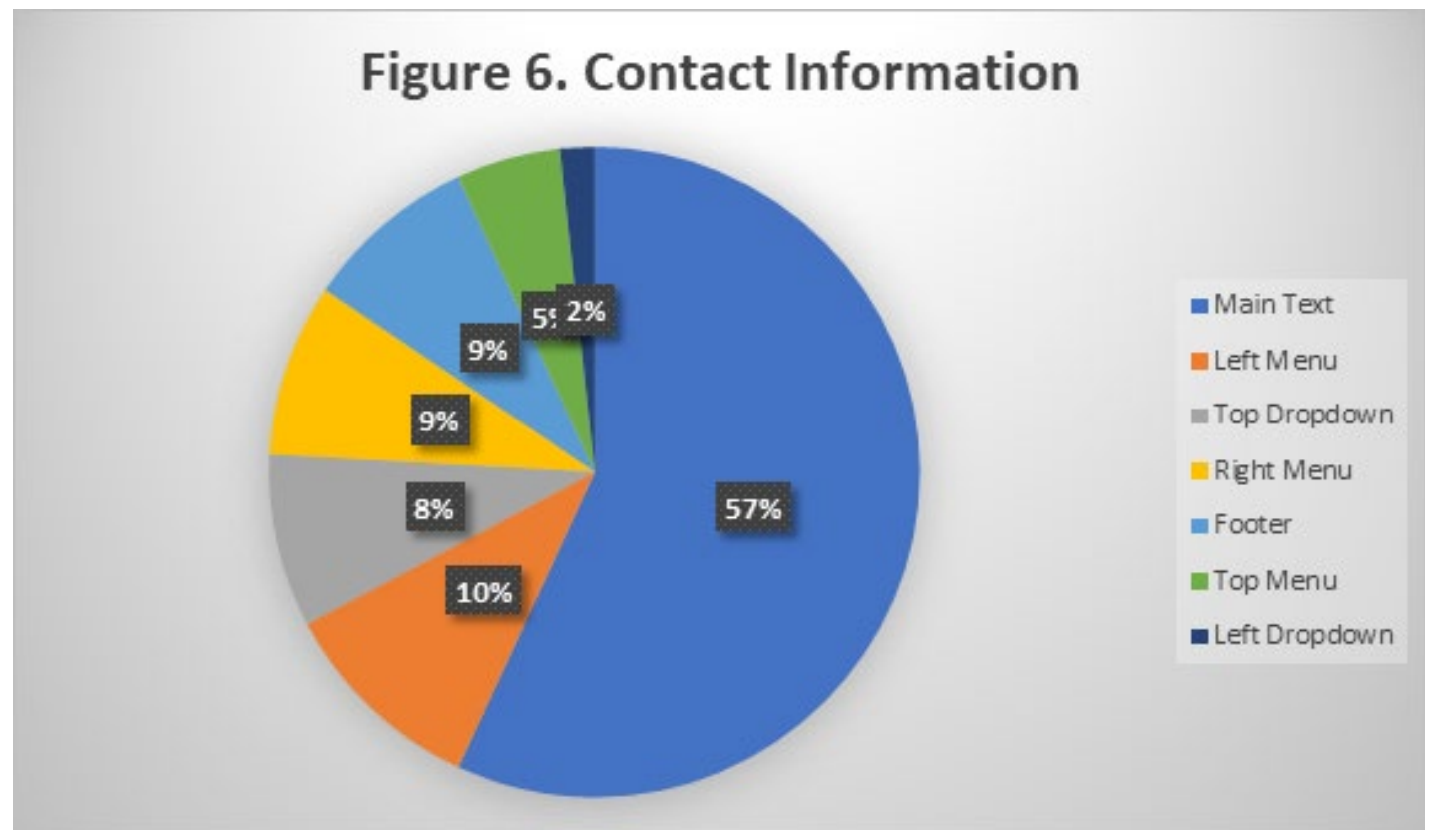


ABOUT THE LIBRARY

This section was either labeled as "About" or was simply text about the library with no heading on the landing page. Including the latter, this content item appeared most frequently in the main text ( $\mathrm{n}=23$, or $42 \%)$, with a fair representation on left menus $(n=15$, or $27 \%)$ and top menus $(n=13$, or $24 \%)$. Three websites located About in a top dropdown $(n=5 \%)$, and one placed it in the footer $(n=2 \%)$. These results are visualized in Figure 7.

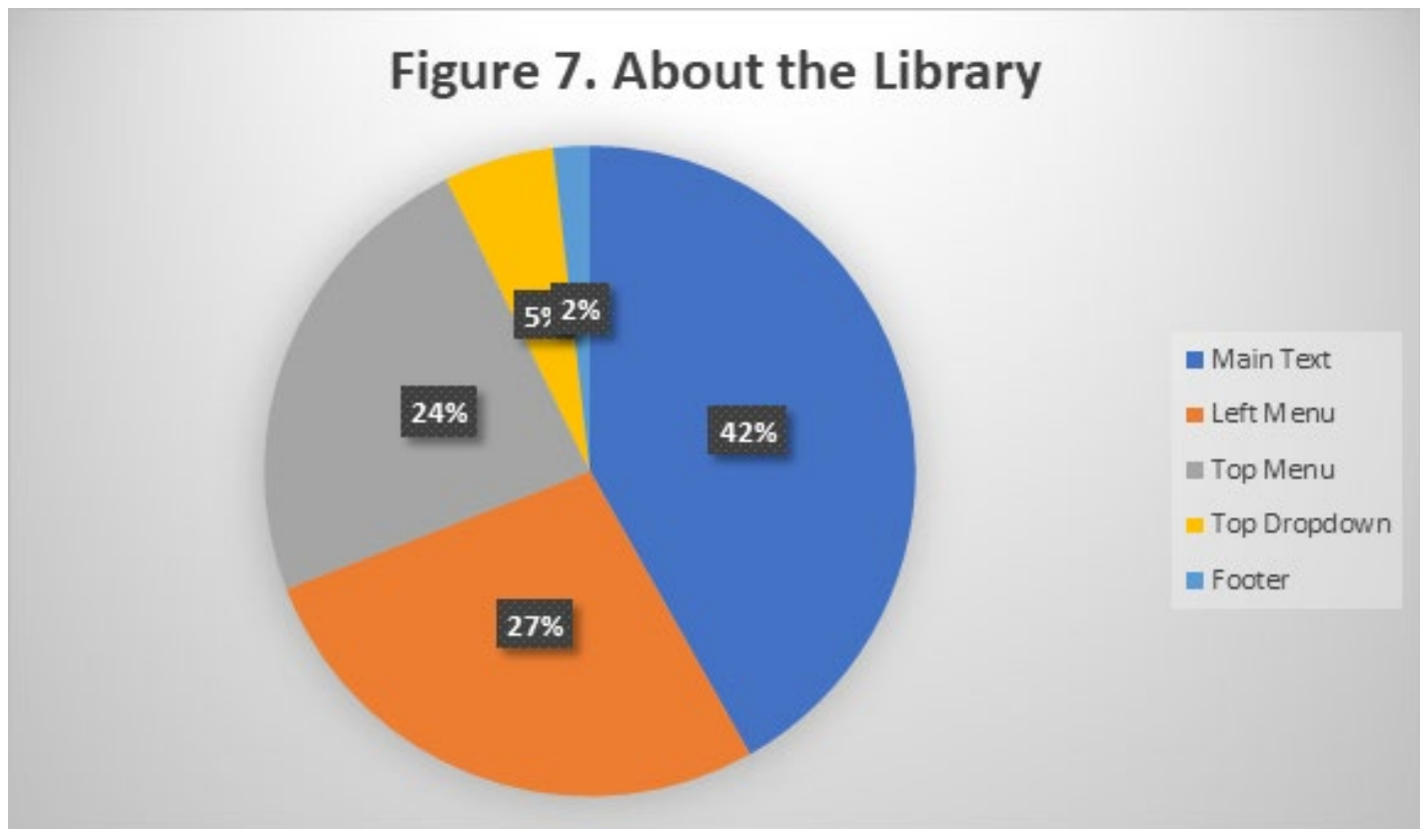

Subject Research Guides

The main text ( $\mathrm{n}=17$, or $36 \%)$ and top dropdowns ( $\mathrm{n}=12$, or $25 \%)$ were the leading places for subject research guides, followed by left menus $(n=8$, or $17 \%)$ and left dropdowns $(n=4$, or $8 \%)$, top menus $(n=4$, or $8 \%)$, a right menu ( $\mathrm{n}=1$, or $2 \%)$ and a right dropdown $(\mathrm{n}=1$, or $2 \%)$, and a footer $(\mathrm{n}=1$, or $2 \%)$. These results are visualized in Figure 8.

\section{Figure 8. Subject Research Guides}

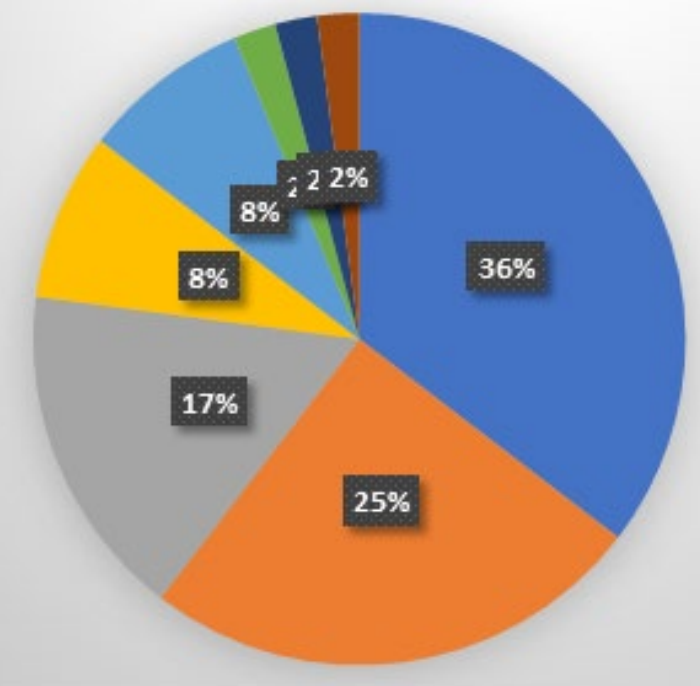

$$
\begin{aligned}
& \text { - Main Text } \\
& \text { - Top Dropdown } \\
& \text { = Left Menu } \\
& \text { = Left Dropdown } \\
& \text { = Top Menu } \\
& \text { - Right Menu } \\
& \text { - Right Dropdown } \\
& \text { - Footer }
\end{aligned}
$$




\section{R3. To what degree is responsive design integrated into theological library websites?}

Each library website was tested on a desktop or laptop and then on a smartphone for functionality and change in layout and navigation. Of those found to be fully functional mobile sites, top and side menus were displayed using collapsed menu icons, and content on the left was stacked on top of content on the right. Four types of websites were discovered in answer to this question: those with fully functional mobile sites, those with partially functional mobile sites (in which most content was available but some features either did not exist, did not work, or were out of reach of mobile scrolling), those with no mobile site at all, and those whose full site was sparse enough that it converted well to mobile without a different version. The most frequent type of website was the fully adaptable to mobile version ( $n=54$, or $66 \%$ ), with 19 (23\%) that were not adaptable at all, 5 (6\%) partially functional mobile websites, and 4 (5\%) full sites that functioned well on a mobile device. These results are displayed in Table 1.

\begin{tabular}{|l|c|}
\hline \multicolumn{1}{|c|}{ TYPE OF MOBILE WebSITE } & NUMBeR OF WebSITES \\
\hline Fully Functional & $54(66 \%)$ \\
\hline Not Functional & $19(23 \%)$ \\
\hline Partially Functional & $5(6 \%)$ \\
\hline Full Site Functional on Mobile & $4(5 \%)$ \\
\hline
\end{tabular}

Table 1: Functionality of Mobile Websites $(n=82)$

\section{DISCUSSION AND CONCLUSION}

\section{Discussion}

The key content of theological library websites as found in this study can be divided into two categories: customer service and research facilitation. Operating Hours, Contact Information, and About the Library fall under the category of customer service, wherein the website functions as what Ganski called "the virtual front door" of the library (Ganski 2008, 38). Indeed, in many cases, this content is an extension of the physical front door of a library, leading patrons to come to the library and interact with the librarians. On the other hand, the Library Catalog, Research Databases, Writing and Citation Help, and Subject Research Guides all fall under the category of research assistance. Each of these content items serves as a guide for research and writing, with varying levels of patron interaction and differing degrees of direct access to resources. Interestingly, library websites seem to make Operating Hours readily available more often than they make the Library Catalog; but this is probably due to the presence of discovery tools, which occurred in just under half ( $n=38$, or $46 \%)$ of the websites in this study. The top three content items (Operating Hours, Research Databases, and Writing and Citation Help) speak to the values of theological libraries; while it would be an exaggeration to say that this sample clearly shows the values of theological libraries across the board, it is interesting to note the apparent emphasis on access to the physical library and its staff, research material, and writing assistance. This makes sense, considering that the primary patron base for a seminary library is the institution's faculty and students, who are deeply engaged in research and writing and need access to resources in a variety of formats and the expertise of information professionals.

The primary navigational path to key content for all items was that it appeared in the main text of the landing page, either through a direct hyperlink or simply as text displayed on the website. The only content items primarily located with any consistency in a menu ( $20 \%$ or more) were About the Library and Subject Research Guides. Of these, a left menu was most frequent for About the Library ( $\mathrm{n}=15$, or $27 \%$ ), whereas a top dropdown was most frequent for Subject Research Guides ( $n=12$, or 25\%). Because this 
study only calculated the most prominent navigational path to key content, the results do not necessarily indicate an overall lack of menus in theological website navigation. Rather, the data of this study suggest that if libraries wish to make key content readily available, they tend to at least locate it in the main text, if not also in a menu.

This study tested the navigability of library websites on mobile devices to assess responsive design. Two-thirds (66\%) of the websites were found to be fully functional in their mobile versions, with only five (6\%) partially functional and nineteen (23\%) not functional at all. The partially functional mobile websites, though happily a small portion of the sample, echo Tidal's 2017 study, which found that the essentials of the website were generally preserved on mobile while certain features were out of reach. In addition to the fully functional, partially functional, and not functional mobile websites, this study found four websites (5\%) that seem to have taken the advice of Rodriguez to "weed nonessential content"; the full websites themselves were so bare and efficient that no adjustment was needed to make the mobile version fully functional and easy to display (Rodriguez 2016, 17). It is encouraging to note that libraries seem to be incorporating responsive design into their website planning, and it would be interesting to see if the percentage of fully functional mobile websites continues to increase in the coming years.

This study originally sought parallels to that of Ganski (2008), tracing the frequency of e-journals, external links, and digital libraries as content items. While this study did find all of these content items as distinct links on the library websites studied, none of them were common enough to be considered key content for theological libraries across the board. Specific links to e-journals, journal lists, and journal indexes only appeared on 28 websites (34\%), as opposed to Ganski's 56 percent (Ganski 2008, 41). External links were found on 20 websites (24\%), as compared with Ganski's 60 percent (Ganski 2008, 42). The presence of a digital library or repository on 21 websites (26\%), although not frequent enough to be considered in the main portion of this study, was far more frequent than Ganski's one (Ganski 2008, 42). This suggests that theological libraries have increased development of a digital library or repository in the intervening decade. The seeming diminishment of e-journal and external website links may be due to the differing methodologies between the studies, the presence of databases and research guides as entryways for e-journals and external website links, or the advent of more digital libraries, potentially lessening the need for external links.

\section{Directions for Further Research}

Future research in this area could calculate theological library website content in terms of the library's mission of research, teaching, public service, and maintaining religious identity (Stover 2001). Content could be coded for each part of the mission and traced to see if one part is weighted more heavily in terms of frequency on theological library websites. This would, perhaps, provide a window into what theological libraries value in a practical sense rather than in the abstract sense given by mission statements.

Additionally, further research into theological library navigation should take redundancy and usability into account. This could involve a more thorough tracing of all the occurrences of key content, calculating how much redundancy of links library websites typically provide and where these are in terms of layout. Calculating the usability of theological library websites could involve a lab testing setup rather than simple documentation of what appears on the websites.

This study supports empirically the anecdotal observation that what a library wants people to know about it is what it will put on the library website. If operating hours and other facets of customer service are important to the library, it will post this information somewhere on the website. Similarly, if research is important, research databases and guides will be in a prominent position on the website. Thus, theological libraries should consider who they are, their mission, resources, and services, when organizing their websites; if the library has special denominational collections or the seminary has a strong lay ministry, the library website should reflect that. In addition to their own unique offerings, libraries should strive to include basic customer service and research assistance through their website by posting key content such as operating hours and by making research databases and guides available. Putting key 
content in the main text of the homepage-perhaps in addition to putting it on menus-will make it more available to potential users. Additionally, to optimize user access to the library website, libraries will do well to continue efforts toward responsive design.

\section{WORKS CITED}

Aharony, Noa. 2012. “An Analysis of American Academic Libraries’ Websites: 2000-2010.” The Electronic Library 30, no. 6: 764-76.

Atla. 2017. “Appendix X: ATLA Institutional and Affiliate Member (with Member Representatives) Directory (2016-2017).” Atla Summary of Proceedings 71: 264-70.

Chow, Anthony S., Michelle Bridges, and Patricia Commander. 2014. “The Website Design and Usability of US Academic and Public Libraries: Findings from a Nationwide Study.” Reference \& User Services Quarterly 53, no. 3: 253-65.

Comeaux, David J. 2017. "Web Design Trends in Academic Libraries-A Longitudinal Study.” Journal of Web Librarianship 11, no. 1:1-15.

Cummings, Joel, Alex Merrill, and Steve Borelli. 2010. “The Use of Handheld Mobile Devices: Their Impact and Implications for Library Services.” Library Hi Tech 28, no. 1: 22-40.

Fang, Xiao, Michael Chau, Paul Hu, Zhuo Yang, and Olivia Sheng. 2006. "Web Mining-Based Objective Metrics for Measuring Website Navigability.” In ICIS 2006 Proceedings, 194-208.

Ganski, Kate L. 2008. “Accessibility of E-Resources from Theological Library Websites.” Theological Librarianship 1, no. 1: 38-45.

Holifield, David. 2012. “The Face of Digital Librarianship.” Journal of Religious \& Theological Information 11, nos. 3/4: 158-160.

Kim, Soojung, and Elizabeth DeCoster. 2011. "Organizational Schemes of Information Resources in Top 50 Academic Business Library Websites.” The Journal of Academic Librarianship 37, no. 2: 137-44.

McMenemy, David. 2007. "Internet Identity and Public Libraries: Communicating Service Values through Web Presence.” Library Review 56, no. 8: 653-7.

Michalec, Mychaelyn. 2006. “A Content Analysis of Art Library Websites.” Art Documentation 25, no. 2: 24-54.

Mohammed, Abubakar, Arminu Garba, and Hafiz Umar. 2016. "University Library Websites in Nigeria: An Analysis of Content.” World Digital Libraries 9, no. 2: 121-30.

Noruzi, Alireza. 2004. “Application of Ranganathan's Laws to the Web.” Webology 1, no. 2: Article 8.

Reitz, Joan M. n.d. “Content Analysis.” Online Dictionary for Library and Information Science. Accessed May 27, 2019.

Rodriguez, Michael. 2016. “Developing Responsive Library Web Sites.” Florida Libraries 59, no. 2: 15-18.

Salisbury, Preston, and Matthew Griffis. 2014. “Academic Library Mission Statements, Web Sites, and Communicating Purpose.” The Journal of Academic Librarianship 40, no. 6: 592-6.

Stephenson, Kimberley. 2011. "Separating the Wheat from the Chaff: What's Really Important in Library Website Design?” The Christian Librarian 54, no. 2: 89-99.

Still, Julie M. 2001. "A Content Analysis of University Library Web Sites in English Speaking Countries.” Online Information Review 25, no. 3: 160-5.

Stover, Mark, ed. 2001. Theological Librarians and the Internet: Implications for Practice. New York: Haworth Information Press.

Thelwall, Michael. 2009. Introduction to Webometrics: Quantitative Web Research for the Social Sciences. New York: Morgan \& Claypool.

Tidal, Junior. 2017. “One Site to Rule Them All, Redux: The Second Round of Usability Testing of a Responsively Designed Web Site.” Journal of Web Librarianship 11, no. 1: 16-34. 
Wilson, Daniel Earl. 2015. “Content and Design: An Analysis of Alabama Academic Library Websites.” The Electronic Library 33, no. 1: 88-102.

Yoon, Ayoung, and Teresa Schultz. 2017. "Research Data Management Services in Academic Libraries in the US: A Content Analysis of Libraries’ Websites.” College \& Research Libraries 78, no. 7: 920-33. 